\title{
Medicosocial Study on the Influence of Indigenous Knowledge on Perception of Disease Status: Using a Cardiovascular Disease as a Model
}

\author{
Ejiofor Augustine Ezika, Ph.D.
}

School of Health and Life Sciences, University of the West of Scotland, Paisley, G15 6AT, United Kingdom.

Received 21 September 2019 • Revised 26 November 2019 • Accepted 27 January 2020 • Published online 1 May 2020

\begin{abstract}
:
Objective: Cultural beliefs may shape understanding of disease. Cardiovascular disease (CVD) is increasing in prevalence in urban Nigerian communities; hence, the aim of this research is to explore spiritual views in this context. Material and Methods: This study employed convenience sampling to recruit 50 participants via word of mouth, posters, handbills and community networks. The author drew from his indigenous knowledge to design tools in collaboration with stakeholders, including the community members, faith leaders and leaders in community healthcare practice; to investigate and explore the views of an urban community members in Nigeria on their indigenous beliefs about factors that contribute to CVD.

Results: The views that emerged in exploring perceived spiritual factors that contribute to CVD were organised into two preceptions, namely: spiritual inflicted diseases influenced by humans and spiritual inflicted diseases influenced by non-humans. The perceived spiritually inflicted diseases influenced by humans are through witchery and sorcery. The perceived spiritual inflicted diseases influenced by non-humans are through Satan, deities, and God. Spiritually inflicted diseases are perceived to be transmitted through pets, such as domestic cats, birds like owls, bats and objects. Perceived spiritually inflicted diseases can only be healed through spiritual means.

Conclusion: In a well-educated, ethnically diverse urban setting the view that spiritual factors have an impact on health and disease is prevalent. Since this may have an impact on healthcare choices, it should be accommodated for in public health planning, and further explored through community-based participatory research.
\end{abstract}

Keywords: cardiovascular disease, indigenous knowledge, Nigeria, spiritual factors

Contact: Ejiofor Augustine Ezika, Ph.D.

School of Health and Life Sciences, University of the West of Scotland,

Paisley, G15 6AT, United Kingdom.

E-mail: Augustine.Ezika@yahoo.com

This is an open access article under the CC BY-NC-ND license

(http://www.jhsmr.org/index.php/jhsmr/about/editorialPolicies\#openAccessPolicy).

J Health Sci Med Res 2020;38(3):193-202 doi: $10.31584 /$ jhsmr.2020737 www.jhsmr.org 


\section{Introduction}

All cultures have systems of health beliefs to explain what causes illness, how they can be cured or treated, and who should be involved in the process. Some societies believe that illness is a result of supernatural phenomenon's, and promote prayer or other spiritual interventions that prevent the spiritual forces from causing misfortunes. ${ }^{1}$ In the past, it was thought that development, urbanisation, modernisation, education or the adoption of Christianity or Islam would lead to the disappearance of beliefs and practices related to witchcraft. However, the current reality in much of Sub-Saharan Africa is quite different. These social and cultural representations have been maintained, transformed and adapted according to contemporary realities and needs. ${ }^{2}$ The literature is replete with anthropological evidence on the perceptions of spiritual variables as factors that contribute to diseases in some cultures around the world. ${ }^{3}$ These views are not taken into account in health literature, and there is a need for a stronger interdisciplinary approach. In light of this observation, this study explored the perceptions of community members in an urban population in Nigeria, in regards to the role of perceived spiritual variables as factors that contribute to cardiovascular disease (CVD).

\section{Theoretical framework}

Kleinman's Explanatory Models (EMs) of illness describe individuals and groups as having different ideas of health and diseases. ${ }^{4}$ A person attaches meaning to the experience of illness by creating narratives describing its causes (aetiology), how it is manifested (symptoms), how it affects the person or the body (pathophysiology), how it is expected to proceed (course) and what should be done about it (treatment). Individuals apply content from their cultural reality to explain each of the five categories in a creative manner, which is motivated by the need to make sense of illness. ${ }^{5}$ Connections among the five concepts form a semantic network guided by symbolic reality. ${ }^{6}$ EMs of illness represents an effort to make sense of illness. By making sense of the illness, patients and their families, as well as health professionals gain a sense of having some control over the illness; for instance, by identifying possible causal agents. If the cause can be established, this in turn often leads to clear ideas about appropriate treatment and the healing process. ${ }^{7}$ All cultures have EMs of illness, because illness is universally viewed as a disruption of life that requires explanations. ${ }^{8}$ However, these explanations are culturally shaped, and show cross-cultural variations. ${ }^{9}$

EMs are incorporated into biomedical, naturalistic, emotionalistic, and personalistic models of illness. ${ }^{10,11}$ The western biomedical model views disease as originating inside the body, due to a specific identifiable medical cause. It emphasises the biological and physical aspects of disease aetiology. ${ }^{12}$ The naturalistic model of illness states that: Illness is due to an impersonal factor, for example, pathogens, malnutrition, obstructions (example: kidney stone), or organic deterioration (example: heart failure). The naturalistic theory has its origins in the work of Hippocrates, and dominates the pedagogy of modern medical schools. Whereas, the emotionalistic model describes illness as being caused by strong emotional distress, including intense anger, jealousy, shame, grief or fright. ${ }^{11}$ The findings reported in this study are embedded in the personalistic model, which attributes illness to interventions by agents, such as humans, witches, sorcerers, non-humans or super-natural forces. A supernatural force might be a deity, or a dead ancestor that causes illness in retaliation for moral or spiritual failings. ${ }^{10}$ If someone has violated a social norm or breached a religious practice; for example, he or she may invoke the wrath of a deity, therefore, their sickness is explained as a form of divine punishment. Recovery from illness arising from personalistic 
causes usually implies the use of ritual and symbolism, most often by practitioners who are specially trained in such arts. ${ }^{10}$

\section{Material and Methods}

Ethical approval was sought and obtained from the School of Health and Life Sciences Ethics Committee, University of the West of Scotland and the Lagos State Ministry of Health, Lagos State, Nigeria. This study employed convenience sampling to recruit 50 participants via word of mouth, posters, handbills and community networks. The inclusion criteria for participants that took part in the study reflected certain characteristics. The participants were Nigerians, residing in a given urban geographical area; whom understood and spoke English, and were between the ages of 20-80. Exclusion criteria included: non-Nigerians, Nigerians outside the age bracket (20-80) and Nigerians residing outside the given urban geographical area. The author drew from his indigenous knowledge to design tools (questionnaires and a semistructured interview) to investigate, and explore the views of urban community members in Nigeria on their indigenous beliefs about factors that contribute to CVD. These tools were designed in collaboration with stakeholders, including the community members, faith leaders and leaders in community healthcare practice. There was health education on modifiable risk factors that contribute to CVD using case stories, environmental print materials and pre-and-post evaluation questionnaires. These tools were used to test the participant's knowledge, and were later used to highlight and discuss the correct answers. The purpose of the health education was not to challenge the indigenous knowledge about CVD. The questionnaires were readministered to the participants three months later at the end of the health education session, so as to find out if their perceptions on how they perceived spiritual variables as factors that contribute to CVD had changed. The views of the participants before health education activities on the modifiable risk-factors that contribute to CVD were compared with their views after the health education activities. McNemars test was carried out to find out if there were changes in responses after this complex intervention. The emerging themes from the survey of the perception of spiritual variables as factors that contribute to CVD were further explored through one-to-one interviews, with each participant; these lasted between 30-60 minutes. The interviews were designed with open-ended questions, so as to allow maximum flexibility and freedom. Additionally, the research questions were modified, sometimes, depending on what was needed to been draw out as a detailed response. ${ }^{13}$ The qualitative data collected in this study was analysed by an approach of thematic analysis presented by Braun and Clark (2006). ${ }^{14}$

\section{Results}

The total number and gender of the participants that attained a certain level of education are shown in Figure 1. The population of the community, wherein the community-based research activities were undertaken, can be described as a well-educated population.

The majority of the participants were first degree graduates. The participants with postgraduate education were least in number. The abbreviations used in Figure 1 below are interpreted as follows: Sec Edu=secondary education which means high school; Graduate Edu= graduate education which means university/college graduation; and Postgraduate Edu=postgraduate education which means postgraduate level.

The views of the participants before the health education sessions, and then three months after the health education sessions are represented in percentage in Figure 2 below. 


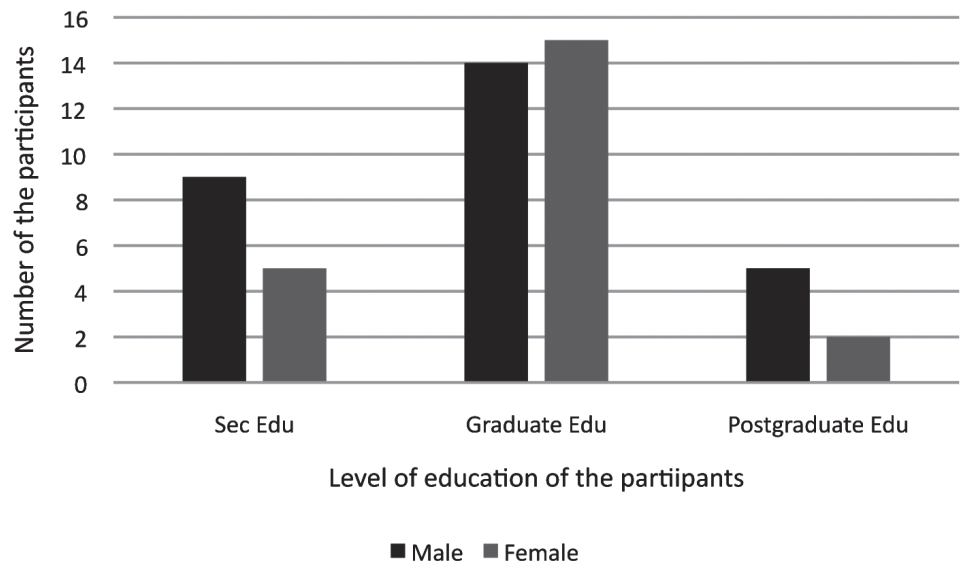

Sec Edu=secondary education, Graduate Edu=graduate education, Postgraduate Edu=postgraduate education

Figure 1 Educational background of the participants

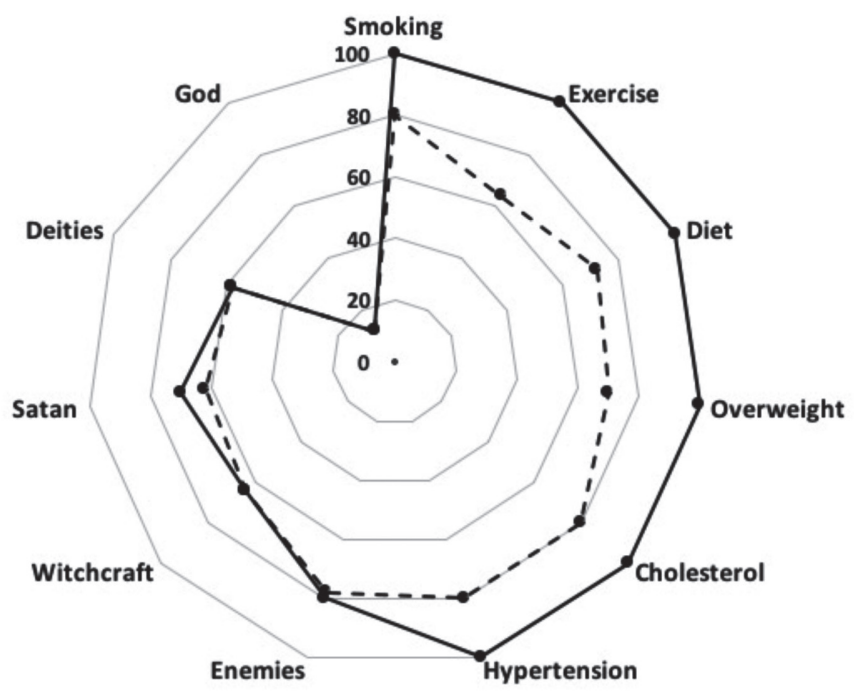

Figure 2 The views of participants before and after health education

While the views on modifiable risk factors that contribute to CVD changed significantly ( $p$-value<0.013), the views on spiritual variables were unchanged after the complex health education intervention. The trend to a decrease in perceptions that Satan and one's enemy as variables that contribute to CVD did not reach statistical significance ( $p-v a l u e=0.134$ and 0.243 , respectively). The difference in these indigenous perceptions, when comparing between those post-graduate/graduate and those with a lower education level, was not significant ( $p$-value=0.205). The three, key themes that emerged in this study are discussed under the following constructs (1) perceived spiritual factors that contribute to cardiovascular disease (2) perceived mechanism for spiritual transmission of diseases influenced by humans, and (3) perceived treatment of spiritually inflicted diseases influenced by humans. 
The Perceived spiritual factors that contribute to cardiovascular disease

In this study, the views that emerged in exploring perceived spiritual factors that contribute to CVD were categorised into two categories, namely: spiritual inflicted diseases influenced by humans, and spiritual inflicted diseases influenced by non-humans.

\section{Spiritual inflicted diseases influenced by}

humans: Emerging from this study was the view that spiritually inflicted diseases influenced by humans are through witchery and sorcery. Some participants in this study were of the opinion that CVD could be as a result of spiritual issues related to witchery. The belief in spiritual variables as factors that contribute to CVD may be influenced by the participants' life experiences, or other variables, such as oral traditions, norms, cultural practices and value system.

"Spiritual factors, such as witches and wizards can contribute to cardiovascular disease"

Some participants in this study argued that belief in the existence of witchcraft is not limited to Nigeria, but cut across Africa.

"In Africa, we believe in what is known as black power, which is associated with witchcraft"

The view that not all health-related issues are spiritually inflicted were emphasized by the participants.

"However, not all health-related issues are spiritually manipulated. In Africa, I would say $35.0 \%$, or even $45.0 \%$ of the diseases people contract are spiritual"

The opinion that witches and wizards can contribute to positive health outcomes through their healing powers were expressed by some participants.

"Witches and wizards can inflict, and also can cure diseases; including heart disease"

The belief that evil people (sorcerers) can spiritually inflict disease to their enemies out of wicked- ness, as a means of revenge or out of sheer jealousy, were expressed by some participants.

"There are sicknesses which medically they say have no cause, they (hospital workers) could not discover the cause... how could you explain the situation wherein a person has a convulsion, what is the name of that sickness? Epilepsy... somebody that is not epileptic until the age of 30 grows up suddenly to become epileptic. Somebody that has epilepsy could have been manifesting the symptoms when he or she was young, but at the peak of achieving something in life they (evil people) afflict him with that sickness"

Participants in this study reasoned that issues relating to land disputes are part of the reason somebody may be afflicted spiritually by evil people.

"If you are involved in one land dispute, or another and the person you are contending the land with feels he has more influence than you, you can go spiritual, and giving them a stroke is one of the ways to bring the person down"

\section{Spiritual inflicted diseases influenced by}

non-humans: One of the views that emerged was that Satan can be responsible for inflicting people with CVD.

"Satan can afflict anybody, he causes accidents and misfortunes; including diseases like strokes, which are not curable"

This kind of quote shows that religion has a lot of influence on how people understand health and sickness. Some participants believe that the devil can afflict someone with diseases.

"From our understanding, the devil has some level of power in the context of spiritual afflictions... yes, it is possible although it is beyond our understanding"

The view that deities can afflict someone with diseases from the power gained from those that worship them was expressed by some participants. 
"People make sacrifices to the deities, and in the process, they (deities) gain power... so the deities can afflict people with the power they have got"

The belief that God can afflict somebody with diseases were expressed by some participants. Others expressed doubts, stating that God only allows Satan to afflict people. This view may have been garnished from Christian religious books.

"When you go to the book of Job, Satan said to God: "this man (Job) you gave him wealth; you gave him everything, why won't he serve you?" God removed all protection from Job to allow Satan to test him. All his daughters died in one day, all his wealth dissapeared in one day, all his houses perished in one day, apart from that, his body was covered all over with boils, to the extent that he could no longer sleep in his bed... that was it, it is not God that afflicted him; however, God permitted it. If you read the last part of the book of Job, God blessed the latter part of his life... he lost seven children, God blessed him with another seven children, more wealth and extended his life"

The findings from this study demonstrate that the participants' perception about diseases is deeply influenced by religion, including African traditional religion and Christianity. Some participants believe that God can afflict someone with a disease, depending on the circumstances, for example, if someone is cursed by God as a result of his/her sins or breach of covenant with God.

"If somebody is fond of committing sin God can afflict that person - going by the words of the bible, or if there is breach of covenant with God, yes, it is possible"

The perceived mechanism for spiritual transmission of diseases influenced by humans

The views of participants on how diseases could be spiritually inflicted on someone were explored. Some said that it is unexplainable, but it is real in an African context.
"There is something called white witchery... just like you talk about the ways particles (electrons) move... can you see them? No, but they do exist. It is more of metaphysics... although it is unexplainable... in an African setting it is real"

Some participants believed that witches and wizards can fly out at night to attack their enemies; whereas, others believed that spiritualists can use birds, such as bats, owls and even pets, such as domestic cats as a vehicle for disease transmission.

"Evil people can use pets, such as domestic cats and birds like owls and bats as vehicles to project (transmit) diseases, including strokes"

Some participants highlighted that means and mechanism of disease afflictions can be through the air, through someone's shadow, images, concoctions and burying of charms underground.

"Yes, they (sorcerers) can afflict through the air you breathe in, even through your (one's) shadow... when one's shadow is afflicted, it can manifest physically in the body"

A participant narrated his experience growing up in a rural community in Nigeria, which may have shaped his worldview that diseases could be transmitted through spiritual means.

"I remember when I was young, there was a man in our village that was contesting a piece of land with someone else... they (our parents and guardians) will be warning us, don't go near this farmland, those that disobeyed paid heavily for it. What he (the owner of the farmland) does is that once he sees somebody's footprint in his farm, the sand with the footprint will be taken to a witchdoctor and the person's leg will be spiritually afflicted"

It was highlighted that distance is not a barrier to the transmission of diseases through spiritual means.

"Even if somebody lives in Japan, they (spiritualists) can call his name and send him a stroke over 
there... that kind of disease cannot be cured in the hospital, only by herbalists or witchdoctors"

Perceived treatment of spiritually inflicted diseases influenced by humans

Emerging from this study is the view that spiritually inflicted diseases can only be healed through spiritual means.

"If you take the person to hospital, the person stays one month, two months, three months... at the end of the day the doctor will tell you we can't help anymore, and the person can be taken back home, but if taken to the herbalist before you know it the sickness is cured"

A participant narrated an experience encountered by a family member that reinforces belief in the spiritual variables as factors that contribute to diseases, which also demonstrates the health-seeking behaviour by the community members.
"A cousin of mine went home; she left from Lagos to the village, and when she came back, she came with Enure (elephantiasis) I told you before... when she was taken to the hospital after some time, the doctors say they cannot do anything about it. Somebody suggested we should take her to the village that it (the disease) is not ordinary. They took us to the spiritualist, and he told us the name of the person that did it and the reason he did it. The spiritualist told us what to do before the disease will be cured... bring this... bring that... before you know it, the disease was cured"

The perceived spiritual factors that can cause and cure diseases is represented in Figure 3. The concept map emerged from the analysis of the views of the participants on this issue.

The perception of 50 community participants on human and non-human factors that can cause or cure diseases.

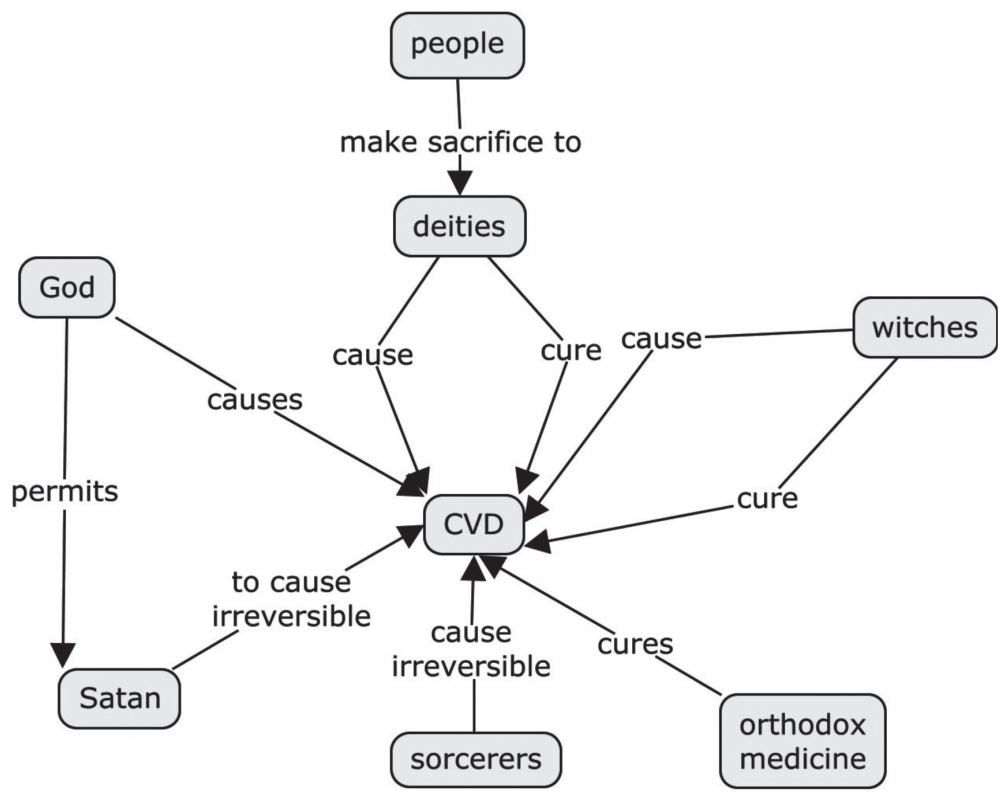

Figure 3 Perceived spiritual factors that can cause and cure cardiovascular disease 


\section{Discussion}

It can be deduced from this study that; religion and cultural beliefs are vital instruments that drive philosophies, perceptions and behaviour across the community where the study was undertaken. An Abrahamic religion, which includes Christianity and the Islamic religion, has the highest number of adherents in Nigeria. ${ }^{15}$ Before the western and middle-east missionaries brought Christianity and Islamic faith to Nigeria, respectively, it has diverse beliefs, cultural and indigenous religious practices, which are usually transferred from one generation to another through oral traditions. This belief system encompasses belief in deities, spirits, veneration of ancestors, worship of mysterious animals such as pythons and use of magic, which are believed to be a source of strength and spiritual guide. ${ }^{16}$ In Nigeria, Abrahamic religious beliefs are sometimes characterised by syncretism of beliefs and practises of traditional African religion. This fact might inform the tendency of some participants to believe that health-related issues could be as a result of spiritual factors.

Illness is universally viewed as a life-disrupting event that requires explanation. Cultural beliefs shape an individual's view or their "Explanatory Model” of disease, in which narratives are created to attach meaning to the experience and manifestation of illness, and further contribute to a sense of control that determines healthseeking behaviour, treatment compliance, and patient satisfaction. ${ }^{11,17,18}$ The assumptions and presuppositions on which Nigerians perceive reality, consciously or unconsciously, aligns to a traditional or primal worldview, in which people are "aware of a mystical power in the universe." This power is ultimately from God, although in practice it is inherent in, or comes from or through physical objects and spiritual beings". ${ }^{19}$ While there is general belief that an omnipotent God has the most power, there is a belief that "the spirits and the living-dead have portions of it; and some human beings know how to tap, manipulate and use some of it". ${ }^{19}$ There is a strong belief that every physical event has an underlying spiritual cause, that can be transmitted through a variety of means, from images and concoctions to physical mutilation, and these beliefs are not incompatible with Christianity in the African setting. ${ }^{3,20}$

These ideas are passed down through generations in stories, myths and rituals; wherein, tribal leaders and elders play a key role as custodians of these ideas. In the light of this study, these views need to be taken into consideration in the development of community health prevention approaches.

It is noteworthy to recognise that there are three, mixed beliefs within the communities where this study was undertaken concerning understanding the aetiology of diseases and how it can be cured. The first may have been influenced by religious books and church doctrines. There are numerous accounts of how Jesus Christ and His disciples healed so many people from different diseases in the Bible, including the case of Job cited by a participant in the community intervention. The second may have been influenced by traditional beliefs in spiritual variables as factors that contribute to diseases. The third are those who believe in modern medicine, and who may decide to seek medical help through orthodox medicine. Having people with these different beliefs and inclinations may influence health-seeking behaviour within the community. Individuals who believe that spiritually contracted illnesses can only be healed through spiritual means may seek help through traditional healers, for example.

The patients' health beliefs can have a profound impact on clinical care. They can impede preventive efforts, delay or complicate medical care and result in the use of traditional remedies that can be either beneficial or toxic. ${ }^{10}$ Differences between patients' and professional's explanatory models may affect health-seeking behaviour, treatment compliance, and patient satisfaction. ${ }^{17}$ Literature 
demonstrates that the explanatory model affects the type of healer or doctor a patient would consult for medical needs as well as the course of treatment they would seek. ${ }^{21}$

\section{Conclusion}

The findings of this research indicate a need for healthcare practitioners to consider the influence of culture and religion in the understanding of diseases and health in general, CVD in particular, while providing services to their patients. It is recommended that CVD prevention intervention strategies should be developed in partnership with local community leaders, including indigenous and faith-leaders, as well as healthcare workers. Innovative approaches to public health education that empower members of the community to make appropriate health decisions are likely to emerge from such collaborations. The author of this study recommends exploration of how indigenous knowledge influences the way individuals, living in a similar cultural context, seek medical care.

\section{Acknowledgement}

The author is thankful to the community members that participated in the study

\section{Conflict of interest}

No conflict of interest declared

\section{References}

1. McLaughlin LA, Braun KI. Asian and Pacific Islander cultura values: considerations for healthcare decisions making. Health Soc Work 1998;23:116-26.

2. United Nations International Children's Emergency Fund. Children accused of witchcraft: an anthropological study of contemporary practices in Africa (United Nations). Dakar: UN Children's Fund (UNICEF); 2010 [cited 2019 Aug 15]. Available from: https://www.refworld.org/docid/4e97f5902.html

3. Nyabwari BJ, Kagema DN. The impacts of magic and witchcraft in the social, economic, political and spiritual life of African communities. International J Humanities Soc Sc Edu 2014;1: 9-18.

4. Tirodkar MA, Baker DW, Khurana NR. Explanatory models of coronary disease among south Asians immigrants. Patient Educ Couns 2011;10:1-7.

5. Kleinman A. Patients and healers in the context of culture: an exploration of the borderland between anthropology, medicine, and psychiatry. Berkeley: University of California Press; 1980.

6. Rodgers C. Illness explanatory models in contemporary research: a critique of the explanatory model interview catalogue [Dissertation]. Pittsburgh: Cory Rodgers; 2012 [cited 2019 Jul 10]. Available from: http://d-scholarship.pitt.edu/11952/ 1/Rodgerscj_ETD2012.pdf

7. Andary L, Stolk Y, Klimidis S. Assessing mental health across culture. Bowen Hills: Australian Academic Press; 2003.

8. White GM. The ethnographic study of cultural knowledge of mental disorder. In: Marsella AJ, White GM, editors. Cultural conception of mental health and therapy. Dordrecht: Reidel; 1982;p.68-95.

9. Weiss MG, Daryl S. Explanatory models in psychiatry. In: Bhugra D, Bhui K, Editors. Textbook of cultural psychiatry. Cambridge: Cambridge University Press; 2007;p.128-140.

10. Carteret M. Culturally-based beliefs about illness causations. Colorado: Elegant Themes; 2013 [cited 2019 Sep 11]. Available from: http://www.dimensionsofculture.com/2011/02/culturallybased-beliefs-about-illness-causation/

11. Vaughn LM, Jacquez F, Baker RC. Cultural health contributions, beliefs, and practices: effects on healthcare and medical education. Open Med Educ J 2009;2:64-74.

12. Weiner BD. Difficult medical problems on explanatory models and pragmatic alternative. Med Hypotheses 2007;68:474-9

13. Polit DF, Beck CT. Nursing research: generating and assessing evidence for nursing practice. $9^{\text {th }}$ ed. Philadelphia: Wolters Kluwer/ippincot Williams \& Wilkins; 2012.

14. Braun V, Clark V. Using thematic analysis in psychology. Qual Res in Psychol 2006;3:77-101.

15. Pew Forum on Religion and Public Life. Appendix B: religious demography of sub-Saharan Africa 2010 [cited 2019 Aug 3]. Available from: https://www.pewresearch.org/wp-content/ uploads/sites/7/2010/04/sub-saharan-africa-appendix-b.pdf

16. Mbiti JS. Introduction to African religion. $2^{\text {nd }}$ ed. Long Groove. Waveland Press; 1991. 
17. Bhui K, Bhugra D. Explanatory models for mental distress: implications for clinical practice and research. Brit J Psych 2002;181:6-7.

18. Kleinman A, Eisenberg L, Good B. Culture, illness, and care: clinical lessons from anthropologic and cross-cultural research. Ann Inter Med 1978;88:251-8.
19. Mbiti JS. African religions and philosophy. $2^{\text {nd }}$ ed. London: Heinemann Publishers; 1990.

20. Asamoah-Gyadu JK. Witchcraft accusations and Christianity in Africa. IBMR 2015;39:23-7.

21. Farmer P. AIDS and accusations: Haiti and the geography of blame. Berkley: University of California Press; 1993. 